\title{
Reply to a comment by Stephen $M$. Chiswell on: "Annual cycles of ecological disturbance and recovery underlying the subarctic Atlantic spring plankton bloom" by M. J. Behrenfeld et al. (2013)
}

\author{
Michael J. Behrenfeld, ${ }^{1}$ Scott C. Doney, ${ }^{2}$ Ivan Lima, ${ }^{2}$ Emmanuel S. Boss, ${ }^{3}$ \\ and David A. Siegel ${ }^{4}$ \\ Received 30 August 2013; revised 18 November 2013; accepted 21 November 2013; published 12 December 2013.
}

Citation: Behrenfeld, M. J., S. C. Doney, I. Lima, E. S. Boss, and D. A. Siegel (2013), Reply to a comment by Stephen M.
Chiswell on: "Annual cycles of ecological disturbance and recovery underlying the subarctic Atlantic spring plankton bloom"
by M. J. Behrenfeld et al. (2013), Global Biogeochem. Cycles, 27, 1294-1296, doi:10.1002/2013GB004720.

[1] Chiswell [2013] suggests that some of the conclusions drawn by Behrenfeld et al. [2013] are likely erroneous because of (1) the method used to calculate specific net biomass accumulation rates $\left(r\right.$; day $\left.{ }^{-1}\right)$ over the seasonal cycle, (2) inconsistencies in the calculation of $r$ and phytoplankton specific cell division rate, $\mu\left(\right.$ day $\left.^{-1}\right)$, and (3) uncertainties in the extrapolation of satellite data to the depth of the seasonal thermocline. Each of these concerns is addressed in the following subsections. We begin with a simple culture-based analogy that clarifies why switching between concentration-based and inventory-based expressions is required for calculating $r$ when the mixed layer varies between shoaling and deepening conditions. This analogy is followed by a more specific mathematical treatment. We then explain why our previous comparisons between $r$ and $\mu$ provide a conservative estimate of predator-prey coupling, followed by a discussion of uncertainties in satellitebased assessments of mixed-layer phytoplankton biomass.

\section{Culture-based Analogy of Phytoplankton Rate Assessments}

[2] In Behrenfeld [2010], Boss and Behrenfeld [2010], Behrenfeld et al. [2013], and Behrenfeld and Boss [2013], the balance between phytoplankton $\mu$ and specific loss rate, $l\left(\right.$ day $\left.^{-1}\right)$, within the mixed layer (i.e., $r=\mu-l$ ) is evaluated from changes in phytoplankton inventory during periods of mixed-layer deepening and from changes in phytoplankton concentration during mixed-layer shoaling. The rational for this approach is perhaps most clearly illustrated using an analogy from the laboratory.

\footnotetext{
${ }^{1}$ Department of Botany and Plant Pathology, Oregon State University, Corvallis, Oregon, USA.

${ }^{2}$ Department of Marine Chemistry and Geochemistry, Woods Hole Oceanographic Institution, Woods Hole, Massachusetts, USA.

${ }^{3}$ School of Marine Sciences, University of Maine, Orono, Maine, USA.

${ }^{4}$ Earth Research Institute and Department of Geography, University of California, Santa Barbara, California, USA.

Corresponding author: M. J. Behrenfeld, Department of Botany and Plant Pathology, Cordley Hall 2082, Oregon State University, Corvallis, OR 97331-2902, USA. (mjb@science.oregonstate.edu)

C2013. American Geophysical Union. All Rights Reserved. 0886-6236/13/10.1002/2013GB004720
}

[3] Consider three nutrient-replete phytoplankton cultures of $1 \mathrm{~L}$ volume that have equivalent growth rates and, at time zero $\left(t_{0}\right)$, have chlorophyll concentrations, [Chl], of $0.2 \mathrm{mg} \mathrm{mL}^{-1}$. The initial chlorophyll inventory, $\Sigma \mathrm{Chl}$, for each culture is therefore $200 \mathrm{mg}$. Assume we are interested in knowing the phytoplankton specific division rate for each culture between $t_{0}$ to time $t_{1}$. Within this time interval, we remove $500 \mathrm{~mL}$ of sample from the first culture, add $1 \mathrm{~L}$ of filtered seawater to the second culture, and leave the volume of the third culture unaltered. At time $t_{1}$, the net division rate in the first culture can only be correctly calculated from measured changes in [Chl], because changes in $\Sigma \mathrm{Chl}$ are impacted by the physical removal of sample between $t_{0}$ and $t_{1}$. Thus, $r=\ln \left([\mathrm{Chl}]_{\mathrm{t} 1} /\right.$ $\left.[\mathrm{Chl}]_{\mathrm{t} 0}\right) /\left(\mathrm{t}_{1}-\mathrm{t}_{0}\right)$. The opposite is true for the second culture. In this case, the correct division rate can only be calculated from changes in $\Sigma \mathrm{Chl}$ because the added $1 \mathrm{~L}$ of seawater dilutes the [Chl], but has no impact on $\Sigma \mathrm{Chl}$. Thus, $r=\ln \left(\Sigma \mathrm{Chl}_{\mathrm{t} 1} /\right.$ $\left.\Sigma C h l_{t 0}\right) /\left(t_{1}-t_{0}\right)$. For the third culture, division rate can be correctly calculated from measured changes in either [Chl] or $\Sigma \mathrm{Chl}$. This analogy demonstrates why switching between concentration- and inventory-based expressions is essential for correctly retrieving division rates from biomass data when purely physical processes are impacting a population between measurement time points. A similar, but field-based, explanation is given in Behrenfeld and Boss [2013].

[4] In Behrenfeld et al. [2013], our aim is to resolve the basis for the sustained imbalances between mixed-layer phytoplankton $\mu$ and $l$ that ultimately yield a bloom climax. Equivalent to the $500 \mathrm{~mL}$ sample removed from the first culture in the analogy above, the purely physical process of detrainment during mixed-layer shoaling represents a loss of mixed-layer biomass, but this loss does not reflect a change in the balance between $\mu$ and $l$ in the mixed layer. As in our culture-based analogy, this balance $(r)$ must therefore be assessed from changes in biomass concentration ( $\mathrm{mg} \mathrm{C} \mathrm{m}^{-3}$ ) because, during shoaling conditions, changes in biomass inventories $\left(\mathrm{mg} \mathrm{C} \mathrm{m}^{-2}\right)$ also include purely physical losses associated with detrainment. This effect is why $d(\ln \Sigma C) / d \mathrm{t}$ in Figure 1b of Chiswell [2013] becomes negative after February.

[5] The second culture in our analogy represents conditions of mixed-layer deepening. As explained in our four papers cited above, the difference between phytoplankton $\mu$ and $l$ is typically 
very small (i.e., $r<<\mu$ ) and can be comparable to the specific rate of change in biomass concentration resulting from the purely physical effects of mixed-layer deepening. Under these conditions (as in the analogy above), the balance between mixed layer $\mu$ and $l$ can only be evaluated from changes in inventories $\left(\mathrm{mg} \mathrm{C} \mathrm{m}{ }^{-2}\right.$ ) because changes in concentration ( $\mathrm{mg} \mathrm{C} \mathrm{m}^{-3}$ ) also register the purely physical impacts of dilution as mixed layer deepening entrains plankton-free deep water into the mixed layer. This effect is why $d(\ln \mathrm{C}) / d \mathrm{t}$ in Figure $1 \mathrm{~b}$ of Chiswell [2013] is negative before February.

[6] Switching from an equation based on biomass inventories to an equation based on phytoplankton concentrations when physical mixing conditions switch from deepening (and greater than the euphotic depth) to shoaling is not only appropriate, but required to diagnose the balance between $\mu$ and $l$ in an evolving mixed layer.

\section{Mathematical Description}

[7] Assuming one-dimensional dynamics, the time evolution of phytoplankton concentration $(d P / d t)$ is represented by [e.g., Evans and Parslow, 1985]:

$$
\frac{d P}{d t}=(\mu-l) P-w \frac{P}{h}=r P-w \frac{P}{h}
$$

where $P=$ phytoplankton concentration and $h=$ mixed-layer depth $(\mathrm{m})$. The last term in equation (1) denotes entrainment during mixed-layer (ML) deepening, where $w=(d h / d t)$ and accounts for the dilution of the phytoplankton in the mixed layer with phytoplankton-free water from below (note, if this deep water has phytoplankton in it, $P$ in the final term of (1) would change to $\Delta P=$ the difference in phytoplankton concentration between the ML and below the ML).

[8] If we simply calculate the rate of change in phytoplankton concentration $\left(\mathrm{mg} \mathrm{C} \mathrm{m}^{-3}\right)$ from satellite observations of $P$ :

$$
\hat{r}=\frac{1}{P} \frac{d P}{d t}
$$

then resultant values of $\hat{r}$ will underestimate $r$ when the ML is deepening and greater than the euphotic depth (e.g., lateautumn and early winter in the subarctic Atlantic), as:

$$
\hat{r}=r-\frac{w}{h} \text {. }
$$

Under these conditions, the value of $r$ can be correctly calculated from changes in ML integrated biomass because

$$
\frac{d(h P)}{d t}=r P h \rightarrow r=\frac{d(P h)}{P h d t} .
$$

Equation (4) is equivalent to equation (1):

$$
\frac{d(h P)}{d t}=P \frac{d h}{d t}+h \frac{d P}{d t}=r P h \rightarrow \frac{d P}{d t}=r P-\frac{P}{h} \frac{d h}{d t} .
$$

During periods of the year when the mixed-layer depth is constant or shoaling, the entrainment term in (5) has a value of zero and the value of $r$ for the mixed layer can be computed from temporal changes in $P$ alone:

$$
r=\frac{1}{P} \frac{d P}{d t} .
$$

It can be noted that (1) and (5) are phytoplankton mass conservation equations and are similar to those used to describe temporal changes in ML temperature, except that boundary conditions and sources/sinks for temperature dynamics are different.

\section{Comparisons of $\boldsymbol{r}$ and $\boldsymbol{\mu}$}

[9] As described above, $r$ must be calculated from temporal change in mixed-layer phytoplankton inventories during periods of convective mixed-layer deepening. As agreed upon in Chiswell [2013], inventories (thus, $r$ ) can be accurately calculated under these conditions as the product of surface concentration and seasonal thermocline depth. When mixed-layer deepening ends, values of $r$ must be calculated from observed changes in phytoplankton concentration (see above). Consequently, these retrieved values of $r$ accurately reflect the balance between $\mu$ and $l$ within the actively mixing surface layer, irrespective of whether this mixing layer is equivalent to or shallower than the seasonal thermocline. Thus, uncertainties in mixing depths during the shoaling period do not compromise our conclusions.

[10] In Behrenfeld et al. [2013], we also compare values of $r$ with estimates of $\mu$. These comparisons are used to illustrate that blooms are consequences of residual differences between the much larger terms of phytoplankton division and loss rates. As values of $r$ are typically one to several orders of magnitude smaller than $\mu$, uncertainties in $\mu$ have no consequences on our conclusions.

[11] Over most of the blooming phase of the subarctic Atlantic (i.e., the period of sustained positive values of $r$ ), the mixed-layer depth is deeper than the euphotic depth $\left(Z_{\text {eu }}\right)$ [see Figure $4 \mathrm{~b}$ in Behrenfeld, 2010]. Accordingly, net primary production (NPP) occurring in the euphotic zone is distributed across all of the phytoplankton in the mixed layer. Thus, mean mixed layer $\mu$ can be accurately calculated from euphotic zone NPP divided by mixed-layer phytoplankton biomass. During final stages of the bloom climax and over much of the subarctic summer, the ML may be shallower than $Z_{\text {eu }}$. Under these conditions, we calculate $\mu$ as euphotic zone NPP divided by euphotic zone biomass [Behrenfeld, 2010]. This approximation slightly underestimates the actual value of $\mu$ within the mixed layer because it includes a contribution from light-limited growth at depth. Our assessment of mixed-layer predator-prey coupling during these periods thus represents a conservative estimate.

\section{Limitations of Satellite Data}

[12] Satellite ocean color sensors retrieve information on water leaving radiance emanating from the first optical depth of the ocean (exponentially weighted toward the surface). Geophysical properties retrieved from these data are representative of the entire water column homogenized by physical mixing, which can be hundreds of meters during winter convective mixing. When net heat flux into the ocean is positive and nocturnal convection is weak, phytoplankton biomass can exhibit significant vertical structure at depths shallower than the seasonal thermocline. Boss and Behrenfeld [2010] used two years of in situ profiling optical float data from the subarctic Atlantic to directly evaluate the significance of this vertical structure on satellite-based assessments of bloom dynamics. These in situ data allowed direct accounting for both biomass vertical structure and entrainment/detrainment effects 
during mixed-layer deepening/shoaling. Their results demonstrate that uncertainties in biomass inventories assessed from satellite data for the subarctic Atlantic have little impact on the conclusions of Behrenfeld [2010] and Behrenfeld et al. [2013].

\section{Summary}

[13] The Disturbance-Recovery hypothesis (DRH) [Behrenfeld et al., 2013; Behrenfeld and Boss, 2013] is an ecosystemfocused framework that better accounts for satellite and autonomous sensor results regarding seasonal plankton dynamics than earlier views focused simply "bottom up" factors controlling phytoplankton division rates. We do not find that the comment of Chiswell [2013] identifies any aspect of our methods that leads to erroneous conclusions. However, as discussed in Behrenfeld and Boss [2013], the DRH framework remains incomplete. Many additional ecosystem processes need to be resolved before a comprehensive understanding of blooms is achieved. Of particular interest are the roles of species succession and selective feeding on biomass accumulation over the blooming phase [Behrenfeld and Boss, 2013].

\section{References}

Behrenfeld, M. J. (2010), Abandoning Sverdrup's Critical Depth Hypothesis on phytoplankton blooms, Ecology, 91(4), 977-989.

Behrenfeld, M. J., and E. S. Boss (2013), Resurrecting the ecological underpinnings of ocean plankton blooms, Annu. Rev. Mar. Sci., 6, doi:10.1146/annurev-marine-052913-021325.

Behrenfeld, M. J., S. C. Doney, I. Lima, E. S. Boss, and D. A. Siegel (2013), Physical-ecological interactions of the subarctic Atlantic annual plankton bloom, Global Biogeochem. Cycles, 27, 526-540, doi:10.1002/ gbc. 20050.

Boss, E., and M. J. Behrenfeld (2010), In-situ evaluation of the initiation of the North Atlantic phytoplankton bloom, Geophys. Res. Lett., 37, L18603, doi:10.1029/2010GL044174.

Chiswell, S. M. (2013), Comment on "Annual cycles of ecological disturbance and recovery underlying the subarctic Atlantic spring plankton bloom", Global Biogeochem. Cycles, 27, doi:10.1002/2013GB004681.

Evans, G. T., and J. S. Parslow (1985), A model of annual plankton cycles, Biol. Oceanogr., 3, 327-347. 